\title{
PEMBERDAYAAN REMAJA DESA WISATA BENDOSARI KECAMATAN PLANTUNGAN KABUPATEN KENDAL MELALUI PELATIHAN KEPEMANDUWISATAAN
}

\author{
Ngasbun Egar ${ }^{1}$, Donny Anhar Fahmi ${ }^{2}$, Fitri Yulianti ${ }^{3}$, Siti Musarokah $^{4}$ \\ ${ }^{1,3,4}$ Fakultas Pendidikan Bahasa dan Seni, Universitas PGRI Semarang \\ ${ }^{2}$ Fakultas Pendidikan IPS, Kesehatan, dan Rekreasi \\ Email : ngasbunegar@upgris.ac.id ${ }^{1}$; pgsdikipdonny@gmail.com ${ }^{2}$; \\ $\underline{\text { fitri_yulianti2907@yahoo.co.id }}{ }^{3}$; $\underline{\text { sitimusarokah@upgris.ac.id }}^{4}$
}

Key word:

empowerment,

tourism village, tour

guide teenager

\section{Abstract}

The success of tourism village development is influenced by many factors. The involvement of the community and all the supporting elements in developing the tourism village becomes the main factor. Community empowerment becomes an alternative solution as an effort to develop tourism village. Bendosari village located in Plantungan District, Kendal Regency is a tourist destination that an interesting tourism potential named Curug Jeglong. It is surrounded by pine forests around it. The most enabling empowerment for Bendosari Village teenagers to support the success of a tourism village development is a tour guide. However, the knowledge and skills that the teenagers have in terms of guidance and English for tour guide is very limited, so it is necessary to conduct guidance and English training for tour guides. The methods used in this training were lecture, discussion, question and answer, drilling, and role play. The results achieved from this activity are 1) the understanding of training participants on the guided tourism improve and 2) Englishlanguage training for tour guide, simple English expressions have been mastered

\section{Kata Kunci \\ pemberdayaan remaja, desa wisata, pemandu wisata}

\begin{abstract}
Abstrak
Pelibatan masyarakat dan semua elemen pendukung dalam kesuksesan pengembangan desa wisata itu. Pemberdayaan masyarakat menjadi solusi alternatif. Desa Bendosari yang memiliki destinasi wisata yang memiliki Curug Jeglong yang dikelilingi hutan pinus. Pemberdayaan bagi remaja Desa Bendosari untuk menunjang keberhasilan pengembangan desa wisata adalah pemandu wisata. Pengetahuan dan keterampilan yang dimiliki remaja dalam hal keepemanduwisataan dan bahasa Inggris bagi pemandu wisata sangat terbatas, sehingga perlu diadakan pelatihan kepemanduwisataan dan bahasa Inggris bagi pemandu wisata. Metode yang digunakan dalam pelatihan ini adalah ceramah, diskusi, tanya jawab, drilling, dan role play. Hasil yang dicapai dari kegiatan ini, yaitu pemahaman peserta pelatihan tentang kepemanduwisataan meningkat. Dari kegiatan pelatihan bahasa Inggris bagi pemandu wisata, kemampuan bahasa Inggris sederhana telah mereka kuasai dengan baik.
\end{abstract}




\section{PENDAHULUAN}

Gerak perkembangan pariwisata dewasa ini merambah dalam berbagai terminology seperti, sustainable tourism development, village tourism, ecotourism, edugreen yang merupakan pendekatan pengembangan kepariwisataan. Salah satu pendekatan pengembangan wisata alternatif adalah desa wisata untuk pembangunan pedesaan yang berkelanjutan dalam bidang pariwisata. Keberhasilan pengembangan desa wisata dipengaruhi oleh banyak faktor, misalnya potensi wisata yang ditawarkan desa wisata itu sendiri. Mutu dan keragaman produk yang dipasarkan juga menjadi penunjang suksesnya desa wisata. Dari dua faktor yang sudah disebutkan, pelibatan masyarakat dan semua elemen pendukung dalam hal ini pihak-pihak terkait dalam mengembangkan desa wisata juga menjadi faktor yang utama penentu kesuksesan desa wisata. Hal ini selaras dengan pernyataan Raharjana (2010) yang menyatakan bahwa pelibatan masyarakat dalam pengembangan desa wisata seharusnya dimulai sejak proses perencanaan. Fitari dan Ma'arif (2017) menyatakan hal yang sama terkait pelibatan masyarakat dalam pengembangan desa wisata. Mereka menambahkan bahwa karena masyarakat merupakan pihak yang mengelola dan menerima manfaat dari keberadaan desa wisata, sehingga perlu adanya pelibatan masyarakat dalam mengembangkan desa wisata dari awal hingga akhir.

Desa Bendosari yang terletak di wilayah Kecamatan Plantungan Kabupaten Kendal merupakan destinasi wisata yang mulai dilirik oleh para wisatawan karena desa ini memiliki potensi wisata yang menarik bernama Curug Jeglong (curug: air terjun, jeglong: menjorok membentuk cekungan). Hutan pinus yang mengelilingi Curug Jeglong dengan udara yang bersih dan alami menambah daya tarik desa ini. Dengan potensi wisata yang dimiliki, partisipasi masyarakat untuk menyukseskan Desa Bendosari menjadi desa wisata sangatlah penting. Mulai meningkatnya minat pengunjung mengunjungi Curug Jeglong sebenarnya dapat menciptakan lapangan kerja baru bagi masyarakat Desa Bendosari, khususnya remaja. Banyaknya populasi kalangan remaja dengan rentang usia belasan sampai puluhan seharusnya lebih diberdayakan sehingga kesukesan desa wisata dapat tercapai.

Melalui pengamatan dan wawancara terhadap pihak pengelola, sudah ada pelibatan remaja dalam mengelola Curug Jeglong sebagai destinasi wisata utama di 
Desa Bendosari. Namun demikian, pelibatan remaja hanya terbatas sebagai pengelola karcis atau tiket masuk dan petugas parkir. Padahal sebenarnya mereka memiliki potensi untuk dikembangkan karena latar belakang pendidikan mereka lulusan Sekolah Menengah Pertama (SMP) dan Sekolah Menegah Atas (SMA). Pemberdayaan yang paling memungkinkan bagi remaja untuk menunjang keberhasilan pengembangan desa wisata adalah pemandu wisata (tour guide). Dalam hal ini remaja memiliki pengetahuan dan keterampilan yang sangat terbatas. Merekan tidak mengetahui dengan baik bagaimana memandu wisatawan yang berkunjung.

Untuk mengembangkan desa wisata pemandu wisata memiliki peran yang sangat penting karena mereka tidak hanya sebagai pengantar wisatawan menuju destinasi-destinasi wisata, namun mereka juga sebagai pusat dan penyebar segala informasi tentang desa wisata itu sendiri. Minat wisatawan untuk mengunjungi desa wisata juga dibangun melalui pemandu wisata. Harum (2012) mendefinisikan pramuwisata atau pemandu wisata (tour guide) sebagai seseorang yang bertugas menemani, memberikan informasi, bimbingan, dan saran kepada wisatawan dalam melakukan aktivitas wisatanya.
Lebih jauh Harum menambahkan bahwa pramuwisata adalah kunci utama yang akan membawa wisatawan mendapatkan pengalaman-pengalaman selama berwisata. Oleh karenanya, pemandu wisata sangat berperan untuk ikut serta mengembangkan desa wisata.

Masalah yang dihadapi oleh remaja Desa Bendosari untuk ikut berperan serta dalam pengembangan Desa Bendosari menjadi Desa Wisata berbasis Edugreen Tourism adalah karena keterbatasan pengetahuan dan keterampilan dalam kepemanduwisataan, Tim pengabdian kepada masyarakat memberikan pelatihan kepemanduwisataan dengan tujuan untuk mempersiapkan remaja Desa Bendosari menjadi pemandu wisata (tour guide) yang memiliki pengetahuan dan keterampilan kepemanduwisataan dengan baik. Selain pelatihan tentang kepemanduwisataan, remaja juga mendapatkan pelatihan bahasa Inggris bagi pemandu wisata dengan tujuan agar remaja tidak gagap atau telah benar-benar siap ketika berhadapan dengan wisatawan mancanegara yang sebagian besar dari mereka berkomunikasi dengan bahasa Inggris.

Berdasarkan analisis situasi di atas, artikel ini bertujuan menggambarkan proses pelatihan, metode, dan luaran yang 
dicapai dari program pengabdian masyarakat.

\section{METODE PELAKSANAAN}

Program pemberdayaan remaja ini adalah bagian dari serangkaian kegiatan pelaksanaan program tahun pertama Ipteks bagi Desa Mitra (IbDM) dan program ini direncanakan berjalan selama 3 tahun. Dalam pelaksanaan program IbDM ini, selain pengembangan fisik dari Desa Mitra, pemberdayaan pada beberapa mitra dari Desa Mitra juga dilakukan. Salah satunya adalah pemberdayaan remaja.

Metode yang digunakan dalam program pemberdayaan remaja ini adalah menggunakan pelatihan dan pendampingan. Pelatihan dalam program ini dibagi menjadi dua, yaitu pelatihan kepemanduwisataan (tour guide) dan pelatihan bahasa Inggris bagi tour guide. Metode pembelajaran yang digunakan dalam pelatihan kepemanduwisataan adalah ceramah, tanya jawab dan diskusi. Sedangkan metode pembelajaran yang digunakan pada pelatihan bahasa Inggris bagi pemandu wisata adalah ceramah, tanya jawab, drilling, dan role play. Pendampingan dilakukan oleh Tim pengabdian kepada masyarakat baik pada saat pelatihan maupun pasca pelatihan.
Pelatihan ini dilaksanakan pada tahun pertama. Pada tahun ke dua pemberdayaan remaja akan difokuskan pada implementasi hasil pelatihan pendampingan di tahun pertama dan pendampingan. Pada tahun ke tiga akan dilaksanakan evaluasi terhadap implementasi pelatihan kepemanduwisataan (tour guide) dan pelatihan bahasa Inggris bagi tour guide.

\section{HASIL DAN PEMBAHASAN}

Terdapat dua jenis kegiatan dalam pelaksanaan program pengabdian kepada masyarakat ini, yaitu pelatihan kepemanduwisataan (tour guide) dan pelatihan bahasa Inggris bagi tour guide. Pelatihan kepemanduwistaan bagi remaja Desa Bendosari ini dilaksakan pada hari Sabtu tanggal 19 Agustus 2017. Peserta pelatihan berjumlah 16 orang. Meskipun pelatihan dapat dilaksanakan dalam satu hari, namun pendampingan juga dilakukan pasca pelatihan. Hal ini dilakukan selain untuk memonitor hasil pelatihan juga keberlangsungan dari pelatihan tetap dapat dijaga. Hasil pengabdian ini akan dipaparkan sebagai berikut.

1. Pelatihan Kepemanduwisataan

Pelatihan kepemanduwistaan bagi remaja Desa Bendosari mengawali kegiatan Pelatihan. Metode yang digunakan pada kegiatan Pelatihan Kepemanduwisataan ini adalah 
ceramah, diskusi dan tanya jawab.

Materi kepemanduwisataan yang diberikan kepada peserta berisi bagaimana menjadi pemandu wisata yang handal. Setidaknya ada beberapa hal yang harus dikuasai oleh pemandu wisata (tour guide), yaitu pengetahuan yang meliputi penguasaan informasi wilayah destinasi wisata, P3K, dan budaya wisatawan dan penguasaan bahasa asing. Selain pengetahuan seorang tour guide juga harus memiliki penampilan yang bersih, tidak berlebihan, dan rapi. Kesehatan dan kebugaran ketika bertugas juga mutlak dimiliki oleh pemandu wisata (Hutagalung, 2014). Dalam penyampaian materi sekaligus dilakukan atau diselingi diskusi dengan cara menghubungkan materi yang diberikan dengan konteks (keadaan lingkungan wisata Curug Jeglong). Dalam kegiatan pelatihan kepemanduwisataan, peserta diberi juga diberi kesempatan untuk bertanya mengenai berbagai hal terkait materi. Di akhir sesi pelatihan yang pertama, peserta bersama-sama pemateri (Anggota Tim IbDM dibantu mahasiswa) menyimpulkan materi pelatihan. Luaran yang dihasilkan dari pelatihan kepemanduwisataan ini adalah pemahaman sebagai pemandu wisata yang handal dapat dikuasai oleh peserta. Hal ini dibuktikan dengan keaktifan peserta menjawab setiap pertanyaan yang diberikan pemateri. Kemampuan peserta dalam menjelaskan atau menyimpulkan materi juga menjadi bukti bahwa pengetahuan mereka akan kepemanduwisataan meningkat. Gambar 1 berikut menunjukkan kegiatan Pelatihan Kepemanduwisataan.

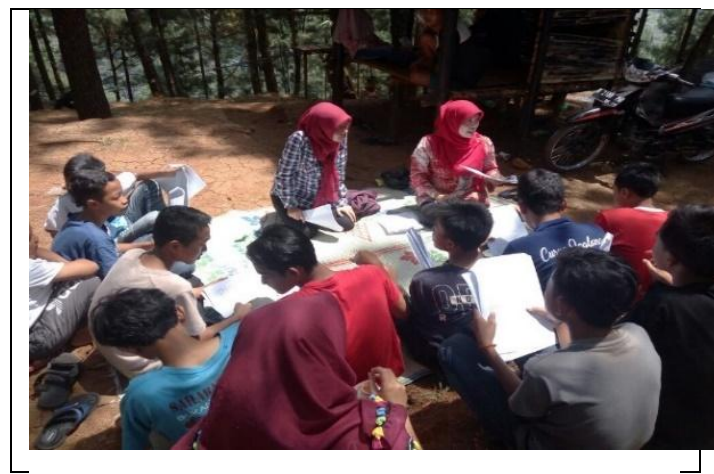

Gambar 1. Pelatihan Kepemanduwisataan

2. Pelatihan Bahasa Inggris bagi Pemandu Wisata

Pelatihan Bahasa Inggris bagi Pemandu Wisata diberikan pada sesi ke dua. Metode yang digunakan dalam pelatihan ini adalah ceramah, drilling, tanya jawab, dan role play. Materi pelatihan berisi berbagai ekspresi bahasa Inggris bagi pemandu wisata yang Tim ambilkan dari tiga sumber yaitu https://www.englishclub.com/english-for- 
work/tour-guide-interest.htm,

https://www.englishclub.com/english-for-

work/tour-guide-safety.htm,

dan

https://www.englishclub.com/english-for-

work/tour-guide.htm disampaikan oleh

pemateri (Anggota Tim dibantu oleh mahasiswa).

Kemudian secara bergantian pemateri dan mahasiswa mendrilling peserta (peserta mengulang ungkapanungkapan bahasa Inggris bagi pemandu wisata). Peserta nampak antusias dan bersemangat menirukan ungkapanungkapan tersebut. Dalam pelatihan ini peserta juga diberi kesempatan untuk bertanya tentang materi. Sesi pelatihan bahasa Inggris bagi pemandu wisata ini diakhiri dengan dengan role play, dimana peserta memerankan diri mereka sebagai pemandu wisata dan wisatawan. Secara bergantian mereka memerankan peran mereka baik sebagai pemandu wisata ataupun wisatawan. Meskipun mereka mengalami kendala ketika menggunakan bahasa Inggris karena kemampuan dasar bahasa Inggris mereka sangat rendah, tapi mereka sangat antusias melakukannya.

Karena kendala penguasaan bahasa Inggris, pada saat role play, peserta masih melihat panduan yang diberikan pada saat pelatihan. Luaran yang dihasilkan pada pelatihan bahasa Inggris bagi pemandu wisata adalah ungkapan-ungkapan bahasa Inggris bagi pemandu wisata yang sederhana dapat mereka kuasai, tapi ungkapan-ungkapan yang panjang mereka masih menggunakan panduan. Gambar 2 menunjukkan aktivitas pelatihan bahasa Inggris bagi pemandu wisata.

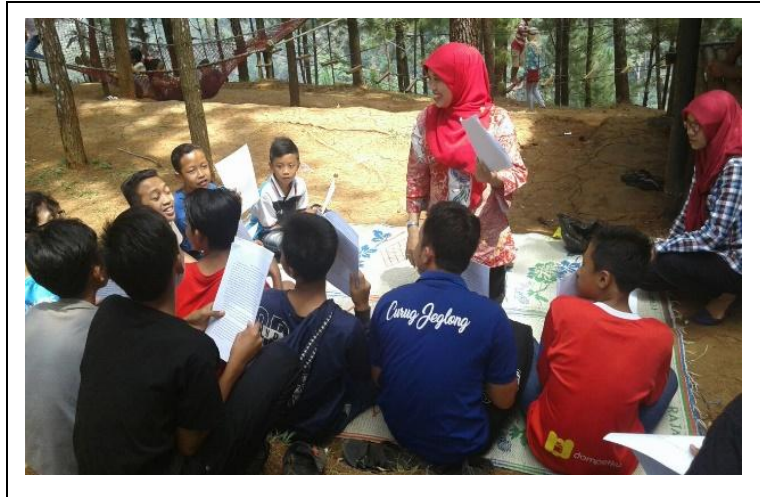

Gambar 2. Antusiasme Peserta saat kegiatan Drilling

\section{KESIMPULAN}

Secara keseluruhan hasil dari pemberdayaan remaja Desa Bendosari pada pelaksanaan program IbDM ini dapat berjalan dengan baik dan lancar. Hasil yang dicapai dari kegiatan ini, yaitu pemahaman peserta pelatihan akan kepemanduwisataan meningkat. Dari kegiatan pelatihan bahasa Inggris bagi pemandu wisata, kemampuan bahasa Inggris sederhana telah remaja kuasai dengan baik meskipun mereka mengalami kendala mengungkapkan ungkapan bahasa Inggris bagi tour guide yang kalimatnya panjang. 


\section{SARAN}

Rekomendasi dari kegiatan pengabdian masyarakat ini adalah untuk mewujudkan Desa Bendosari Kecamatan Plantungan Kabupaten Kendal menjadi Desa Wisata Berbasis Edugreen-Tourism hendaknya pendampingan terhadap remaja dilakukan secara berkesinambungan agar pemahaman dan kemampuan dasar yang telah mereka miliki melalui pelatihan kepemanduwisataan dan pelatihan bahasa Inggris bagi pemandu wisata dapat terus dipertahankan dan ditingkatkan. Remaja juga seharusnya terus menerus berlatih mengucapkan ungkapan-ungkapan bahasa Inggris bagi pemandu wisata agar dapat bersama-sama komponen yang lain ikut serta mengembangkan Desa bendosari menjadi Desa Wisata berbasis Edugreen Tourism.

\section{Ucapan Terima Kasih}

Terima kasih kami sampaikan kepada Kemenristekdikti yang telah membiayai secara penuh program IbDM ini. Terima kasih juga kami sampaikan kepada Rektor Universitas PGRI Semarang dan LPPM Universitas PGRI Semarang yang telah sepenuh hati memberikan motivasi, mengarahkan, dan mendukung secara penuh kegiatan IbDM ini.

\section{REFERENSI}

Fitari, Yessi dan Ma'arif Samsul. 2017. Manfaat Pengembangan Desa Wisata Wonolopo terhadap Kondisi Sosial, Ekonomi, dan Lingkungan Masyarakat Lokal. Jurnal Wilayah dan Lingkungan, P-ISSN: 2338-1604 dan E-ISSN: 2407-8751 Volume 5 Nomor 1, April 2017, 29-44

Harum, Agus. 2012. Peranan Pramuwisata Dalam Memberikan Layanan Kedatangan Dan Keberangkatan. Di akses pada tanggal 8 September 2017 di http://akademipariwisatakpg.blogs pot.co.id/2012/02/perananpramuwisata-dalammemberikan_16.html

Hutagalung, Jefri. 2014. Menjadi Seorang Tour Guide yang Baik. Diakses pada tanggal 15 Agustus 2017 di https://jefrihutagalung.wordpress.co $\underline{\mathrm{m} / 2014 / 04 / 09 / \text { menjadi-seorang-tour- }}$ guide-yang-baik/

Raharjana, Destha Titi. 2010. Membangun Pariwisata Bersama Rakyat: Kajian Partisipasi Lokal dalam Membangun Desa Wisata di Dieng Plateau. 
Jurnal Kawistara-Destha Titi

Raharjana

https://www.englishclub.com/english-forwork/tour-guide-interest.htm, diakses pada tanggal 15 Agustus 2017

https://www.englishclub.com/english-forwork/tour-guide-safety.htm, diakses pada tanggal 15 Agustus 2017

https://www.englishclub.com/english-forwork/tour-guide.htm diakses pada tanggal 15 Agustus 2017 